\section{SPECIES DISTRIBUTION}

\section{Rapid adaptation}

Global Change Biol. 21, 4320-4332 (2015)

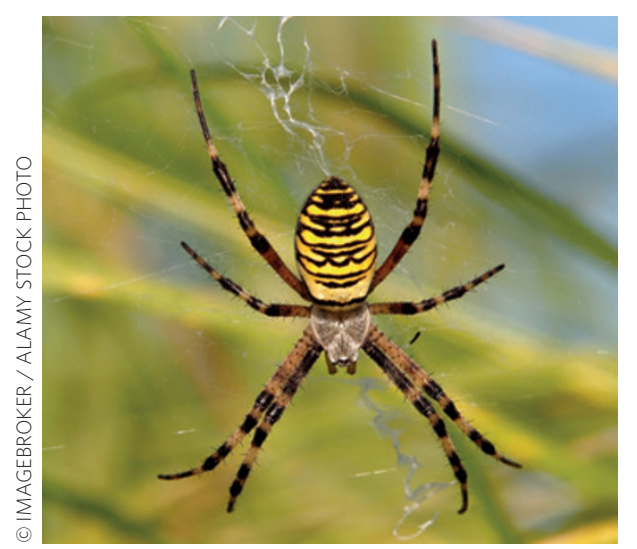

Expansion of species' poleward range margins is frequently attributed to climate change, but the role of rapid evolutionary adaptation in mediating or even driving such expansions remains highly uncertain. Rapid evolutionary adaptation in scattered rangeedge populations is usually expected to be severely limited by low standing variation and mutational input. However, in cases where formerly isolated genetic lineages are once again exposed to one another, genetic mixing may be sufficient to facilitate rapid evolutionary change.

Henrik Krehenwinkel from the Max Planck Institute for Evolutionary Biology and co-workers investigate the European wasp spider (Argiope bruennichi), which has undergone remarkably rapid (and well-observed) range expansion since the 1930s. They use ecological niche modelling, thermal tolerance experiments and analysis of gene expression divergence to show that invasive populations have undergone genetic adaption for cold tolerance as they encountered novel climatic conditions. Furthermore, they find that alleles from East Asian and Northern European populations have contributed to the new adaptations during expansion.

\section{IMPACT ASSESSMENT}

\section{Geoengineering challenges} Climate Law 5, 111-141 (2015)

Geoengineering is moving from modelling to field experiments, with potentially significant environmental, social and ethical impacts. Impact assessments are normally undertaken to determine the risks of such activities. But new research suggests international law is currently insufficiently tailored to the particular assessment challenges posed by geoengineering.

Neil Craik from the University of Waterloo, Canada, reviewed existing customary international and treaty law on environmental impact assessments to consider how legal principles might apply to geoengineering experiments. He found some concerning gaps.

Assessments are normally triggered by the likelihood of significant environmental damage, but that may be insufficiently precautionary in light of public concern about geoengineering and its uncertain impacts. Moreover, assessments normally focus on physical impacts, but social and ethical concerns around the moral hazards of geoengineering and technological lock-in may need to be included in the process. Also, despite the inherently boundary-crossing nature of geoengineering, there is currently
The South Asian summer monsoon is a dominant weather system, bringing heavy rains to the subcontinent from April to September. The people and economy of the region depend on the monsoon rains for agriculture, water supplies and hydroelectricity. However, the future behaviour of the monsoon is uncertain under climate change, with models producing contrasting results.

Xiaolong Chen and Tianjun Zhou, of the Institute of Atmospheric Physics, Chinese Academy of Sciences, Beijing, investigate the source of uncertainties in projections of the monsoon. They analysed simulations from 35 CMIP5 climate models under a highemissions scenario. A wide spread of warming is projected from the models, resulting in the uncertainty of future monsoon circulation.

Further experiments show sea surface temperature warming in the Indo-Pacific Ocean as a dominant source of uncertainty in the monsoon rainfall projection. This warming, particularly in the western central Pacific, alters the east-west atmospheric temperature gradient and modulates moisture transport. This study highlights the role of Pacific Ocean warming in monsoon onset and withdrawal, with further research needed to constrain model projections. no international institution through which consultations over assessments can occur.

Lawmakers have considerable work to do before they can confidently claim that environmental impact assessments can provide scientific, normative and public justifications for geoengineering to move into the field.

\section{SEA ICE}

\section{Regional loss impacts \\ J.Clim. http://doi.org/852 (2015)}

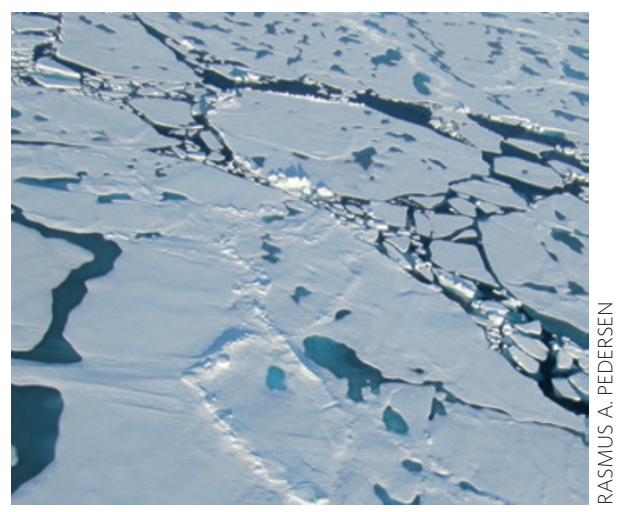

Reduction in Arctic sea ice cover contributes to amplified warming in this region, and, at the same time, it can impact the climate in lower latitudes. The reach of these effects not only depends on the total sea ice loss but also on the geographic location of this loss, although this is not yet fully understood.

Rasmus A. Pedersen, from the University of Copenhagen and the Danish Meteorological Institute, Copenhagen, and colleagues investigate the effect of regional Arctic sea ice loss on local and more remote climates. They use model simulations to examine the atmospheric response to a decrease in sea ice cover in either the Atlantic or Pacific sectors.

Both scenarios result in overall warming over the Arctic and reduced winds in the mid-latitudes. However, important differences arise in the location of these effects. Melt in the Atlantic sector results in increased temperatures over Greenland, but when the melt occurs in the Pacific sector, this warming is not observed. Winds over Europe and Eastern Asia are reduced in both scenarios, but weaker winds over the Atlantic Ocean are only observed for ice loss in the Atlantic sector.

The different locations of the impacts of regional sea ice loss need to be considered in projections of climate change, particularly for the Greenland ice sheet. 